\title{
The Interaction between Genericity and the Formal Performances of the Verb in Middle Construction
}

\author{
Xiuwei Li \\ Department of Foreign Language \\ Huanghe Science and Technology College \\ Zhengzhou, Henan, China \\ e-mail:1xw375@aliyun.com
}

\begin{abstract}
There is no simple one-to-one relationship between genericity and a verb's performance in tense and aspect. In middle constructions, the interaction between the referents of the overt clausal elements brings a complex interaction between genericity and a verb's performance in tense and aspect. The implicit agent pose no remarkable influence on the genericity and the performance of verbs in tense and aspect. Different acceptabilities of middle constructions are created by different tenses or aspects.
\end{abstract}

Keywords-Genericity; Tense and aspectual performance; Middle Construction; Acceptability

\section{INTRODUCTION}

Since the 1980s there have been 3 traditions in studying English Middle Construction: 1. the transformational tradition tries to describe the process in which the transitive verb construction is transformed under the influence of an abstract clichés into Middle Construction, such as Keyser \& Roeper,[1]Carrier \& Randall,[2]Stroik,[3] [4] [5]Hoekstra \& Roberts[6] and Authier \& Reed[7], etc.; 2. the generative tradition probes into the change of the verb's conceptual structure and the projected syntactical structure, such as Roberts,[8]Fagan,[9][10]Massam,[11]Zribi-Hertz,[12]Ackema $\&$ Schoorlemmer,[13] [14] Iwata[15] etc.; 3. the cognitive tradition makes an effort to study the semantic features of the construction, such as Kimihiro \& John, [16] Kristin and Liesbetheyvaert, [17]Kristin and Nele [18] etc.

Among these efforts, the tense and aspectual performance of the verb is under hot debate. Keyser \& Roeper[1]point out that past tense is not acceptable in middle construction because it denotes generic sentences, stating propositions which are believed to be true in a general sense, not reporting a specific event fixed in time; middle verbs never appear in progressive form, because similar to static verbs, they are not used to depict an event. Fagan [9] thinks progressive middle construction will be acceptable if it describes a continuative change of a state. Iwata [15] further points out that genericity is a typical characteristic, not the defining feature, of middle construction, and as a result, some middle sentences can appear in past tense, progressive and even perfective form.

There are similar disputes in relevant research in China. one scholar deduces the non-temporal feature of middle construction based on Langacker's "virtue reality", and concludes that verb in middle construction can only appear in simple form - simple present; [19] another scholar makes it clear that in BNC web, there are many middle constructions in which the verbs may take past tense or progressive, and even perfective forms. [20]

The basic assumptions of Keyser \& Roeper, Fagan and Iwata fall under the same umbrella - verbal performance is decided by the genericity of middle construction. In the following parts, these points will be discussed under the two topics- the multiple representations of genericity, and the aspectual and tense performances of the verb in middle construction.

\section{MULTIPLE REPRESENTATION OF GENERICITY}

Genericity is originally a term used in predicate logic. It refers to the propositional characteristics born from the generic quantifier added to the function of the proposition. [21] In semantics, genericity refers to the generalization of entities or situations of the same type. [22] The main carrier of genericity is the generic statement. When it is specified in language, generic sentences will be born. In China, scholars mainly focus on the logic or cognitive motivations of kind-referring sentences, while no detailed investigation is posed on the origin of genericity of English sentences. [23] [24] [25]

Krifka et al. [26] classified generic sentences into kind-referring NPs and characterizing sentences. The former define types of things instead of specific entities, and thus genericity originates from the kind-referring meaning of the NPs; the latter report the general features summarized from specific episodes and facts, thus the genericity comes from the repetition of events denoted by the predicate verb. For example:

1 a. Ravens are black.

b. Tigers have stripes.

2 a. John smokes a cigar after dinner.

b. A potato contains vitamin $\mathrm{C}$, amino acids, protein and thiamine.

Subjects "Ravens" and "Tigers" in (1) denote types of raven and tiger, or specific sets made up of ravens or tigers, not specific entities. The whole clauses of the two state the 
characteristics of the types and the genericity of them come from the subject NPs, so both are kind-referring sentences. Subjects "John"and "a potato" in example (2) separately refer to a specific individual and a type, but either the characteristics or habit is regular, so they are characterizing sentences. From above, it is necessarily conclusive that clausal genericity originates from the genericity of the subject NPs or the genericity of the predicate.

\section{A. Multiple tense and aspectual representation of generic sentence}

Originated from formal logic, semantic analysis just deals with genericity with no consideration of time and space, let alone the actual linguistic use. From examples (1), (2) depicted by Krifka et al, at least for kind-referring sentences the verbs may appear in past tense form, showing the event, state, process or relationship experienced by entities denoted by the subject NPs. But Krifka et al don't associate genericity and the verb's tense and aspectual performances, for their investigations are confined to the universal logic-semantic categories. Thus they provide not enough evidence to support their conclusion that verbs in middle construction can only appear in simple present form. In fact, the verb's performances in generic sentences are richly colorful.

3 a. Dodos lived in Mauritius and (they) became extinct in the 18 th century.

\section{b. Dinosaurs, which are now extinct, were very large.}

4 a. He was always kissing and touching her and her sisters.

\section{b. I have always loved you.}

Genericity of a, b in example (3) comes from the subject NPs. Both report the general conditions of Dodos or Dinosaurs. Just because the conditions were posed in past periods, the verbs were used in past tense forms. Subject NPs in example (4) are both NPs for specific reference but (4a) represent a repeated action that can be extended into a state, while (4b) directly depicts a static mental inclination. Both are related to the attitudinal inclination of the persons denoted by the subject NPs, so they are characterizing sentences.

In conclusion, these examples make it clear that in generic sentences (excluding the present simple), the verb may also appear in past simple, progressive and even perfective. Once logic-semantic reference is combined with specific situations, a generic sentence will show variability in tense and aspectual performances. Genericity in a logic sense is beyond the limitation of time and space. There is no simple one-to-one relationship between genericity and the tense and aspectual performances of verbs in grammatical sense. The dislocation between genericity and the formal performances of the verb in middle construction reflects the conflicts between the infinity of the object world and that of human's cognitive and expressive infinity.

\section{B. A cognitive interpretation of multiple tense and aspectual representations in generic sentences}

In Langacker's sense, no matter how complex the internal structure is, a process will be an event in a cognitive sense if there is a complete energetic transference [28][29]. That is, a single energetic transaction is an important attribute of an event. In the linguistic sense, the eventivity of a clause lies in its description of a single factual energetic transference. If the transference is multiple then the eventivity will be lowered. Based on this understanding, it will be observable whether there is a necessary connection between eventivity and verb's tense and aspectual performances.

5 a. We visited a factory last Friday.

b. He left ten minutes ago.

6 a. In those days they sowed wheat by hand.

b. The boy sold newspapers for a living.

7 a. Before liberation we lived in Beijing for five years.

b. This town was once a beauty spot.

Apparently, clauses in example (5) are both for events, but they are evidence to show the compatibility between past tense and eventiveness, not the incompatibility between non-eventivity and past tense. In example (6), both imply certain eventivity, for there are complete energetic transferences. But the transferences are not single, and thus the eventiveness is reduced. The two clauses in example (7) are non-eventive, for there are no energetic transferences. In all, there is no correspondence between past tense and eventivity. That is, past tense does not necessarily mean eventiveness. Sentences in the forthcoming example (14) are not accepted by some grammarians, because they assume past tense can only be explained in an eventivity sense. In fact, these sentences can also be interpreted in non-eventive sense. The eventivity in example (14) doesn't conflict with past tense - this is the reason why they are acceptable by other grammarians.

Progressive is typically used to show the ongoing action at the time of utterance, for example:

\section{$8 \mathrm{~A}$ : What are you doing}

B: I'm writing a letter.

In the dialogue depicted in example (8), it is clear that progressive represents a single energetic transference, but compared with the past tense, there are differences. Past tense represents a complete event, while in example (8), the progressive shows an incomplete accumulative event. In this comparative sense, progressive implies eventiveness to a certain degree. In other words, there is a potential for an eventivity explanation of the progressive. This is clarified in examples (9), (10).

9 a. Jane is studying law while her sister is doing physics.

b. He is working in a chemical factory these days.

10 a. She's always borrowing money and forgetting to pay me back.

b. The postman is always putting your letters into my letterbox.

While clauses in example (9) are mainly concerned with temporariness, clauses in example (10) are not, but with the mental or behavioral inclination and the negative attitude of 
the speakers. That is to say, progressive can also get a non-eventiveness explanation.

Compared with past tense and progressive, the association between perfective and eventiveness is looser. The focus of perfective is not the past event but the association between past event and the moment of the utterance. For example:

11 a. He's turned off the light.

b. His sister has been an invalid all her life.

In example (11), (11a) reports the influence of past event on the situation at the time of speaking, while (11b) shows the temporal relevance between the past situation and the situation at the time of speech. Both imply non-eventiveness to a certain degree, with the latter implying a higher level. In short, perfective does not just mean eventiveness.

Past tense, progressive and perfective are all relevant to eventiveness, but this doesn't mean they can't represent non-eventive genericity. If we say a self-dependent patient subject clause is not compatible with past tense, progressive, and perfective, we'll be wrong, for, in this case, we hold the presupposition that past tense, progressive and perfective can only show eventiveness, not genericity.

\section{THE MULTIPLE TENSE AND ASPECT REPRESENTATION IN MIDDLE CONSTRUCTION}

\section{A. I wata's research}

Most researchers believe that in middle construction, the tense and aspectual performance of the verb is within confinement. Among them, Iwata is typical.

According to the role played by subject NPs in the event denoted by the VP, Van Oosten[27] classified the patient subject middle construction into two groups: obligatory patient subject clauses and self-dependent subject clauses. Iwata regards the former as typical middle construction showing influence posed by things denoted by the subject NP on the event denoted by the VP. The latter is also middle construction though there is no similar influence, for it shares the same structural features [15]. If clauses of the first group take generic NPs as the subjects, they will be incompatible with past tense and progressive, but if we add these in the subject NP for specific reference, then those sentences in example (12), which are considered unacceptable by Keyser, \& Roeper, they will be related to specific events, becoming the acceptable expressions in example (13).

\section{2 a. Chickens are killing easily.}

b.Bureaucrats are bribing easily.

\section{3 a. These Chickens are killing easily.}

\section{b. These Bureaucrats are bribing easily.}

Clauses in example (13) may appears not only in present simple, but also in past tense, progressive, perfective, because they depict specific events. [15] The following sentences whose acceptability is refuted by Keyser \& Roeper are therefore acceptable.

14 a. Yesterday, the mayor bribed easily, according to the newspaper.

b. At yesterday's party, the kitchen wall house painted easily.

c. Grandpa went out to kill a chicken for dinner, but the chicken he selected didn't kill easily.

d. If it hadn't been for the weather, my wet kitchen floor would have waxed easily.

By deduction, Iwata set up the correspondence between the reference and the verb's formal performances in middle construction: if the clause is generic, then past tense and progressive are not acceptable; if the clause is eventive, then past tense, progressive and perfective can be used. Conversely, if the verb appears in past tense, progressive or perfective, the clause will be eventive, not generic.

\section{B. The origin of genericity in middle construction}

If certain relevance does exist between genericity and verbal performances, it will be one of representation, not of cause-effect: the verb's formal representation is the specific expression of genericity in the clause. Though verb's tense and aspectual performance is not the source of the genericity of middle construction, it impacts greatly on the genericity.

The holistic semantic of middle construction can be depicted as the following: the internal attribute of the thing denoted by the subject NP causes or permits the act denoted by the VP to be actualized in the way denoted by the adverbial phrase. Based on this, four structural components can be deduced: agent, act, patient and adverbial. Genericity of middle construction exists in the attributes of, and the interrelationship between, the four elements.

There are two contradictory opinions on the origin of genericity in middle construction: one focuses on the relation between verb and genericity, holding that genericity derives from the quantification over the event [30]; the other focuses on the relationship between the implicit agent and genericity, holding that genericity comes from the quantification over the entity [10]. Here, we following Langacker's treatment, holding that grammar is a single-layered symbolic unit composed of basic lexical units [28]. It can be deduced that clausal genericity is decided by the interaction between lexical units, not a particular single element. The interaction between the subject NP, the finite verb and the adverbial is decisive to the genericity of middle construction.

\section{The interaction between the formal representation of the} verb and genericity in kind-referring middle clause

According to the generalization of the holistic meaning of middle construction mentioned previously, and considering the research of Achema \& Schoorlemmer, Iwata, Kristin \& John, Davidse and Liesbetheyvaert, the meaning of middle construction can be formalized as follows:

(The property of) $\mathrm{X}$ cause/ let/ permit/ facilitate the $\mathrm{V}$-ing (of something) by anyone/someone (to be) ADJ.

From this gestal, three subject-verb structures can be observed: the innermost, [the $\mathrm{V}$-ing of $\mathrm{X}]$ [by anyone/someone]; the intermediate, [the $\mathrm{V}$-ing of $\mathrm{X}$ by anyone/someone][ to be 
easy]; and the outermost, [the property of $\mathrm{X}][$ cause/ let/ permit $\cdots \cdots]$ 。 The innermost $\mathrm{S}-\mathrm{V}$ [the $\mathrm{V}$-ing of $\mathrm{X}][$ by anyone/ someone] is always lexicalized as a verb root in a specific sentence [31], and its influence on genericity is slight. What creates a substantial influence on genericity is the intermediate $\mathrm{S}-\mathrm{V}$ and the outermost $\mathrm{S}-\mathrm{V}$. The outermost $\mathrm{S}-\mathrm{V}$ is mainly concerned with kind-referring middle construction, for example:

\section{Sports cars sell quickly.}

In example (15), the generic NP is just one source of genericity, while predicate verb and adverbial also contribute. The generic meaning of the clause can be described as:

\section{GEN [[sports car] [sell]][quickly]]}

This configuration meansin general, for any sports car, its characteristics will let, cause or help selling to be quick at any time.

In specific expression, if the verb form is changed, acceptability will be reduced, even to zero, for example:

\section{Sports cars sold quickly.}

If people do not dwell much on delicacy, but instead recognize "type" as a single cognitive unit, they will take it as stereotypical category and focus on the integrated whole. In this sense, kind-referring sentences will tolerate counterexample. [25] Certainly, counterexamples should not threaten the truth of the whole. When we use past tense form of the verb in example (16), there will be a certain challenge posed by the counterexample, but it is not enough to conceal the truth of the statement as a whole. So even if its acceptability is suspectible, it is self-evident in some specific situation, for past tense can be used to represent the general situation or repetitive event in the past time and there is no great conflict against genericity of the subject NP. If we change it into example (17) to limit the range of the NP's genericity, it will gain an even higher acceptability

\section{Some sports cars sold quickly.}

But, if we change the form of the verb in (15) into progressive, we will get example (18), whose acceptability needs some specific analysis.

\section{Sports cars are selling quickly.}

One important characteristic of the progressive is its temporariness, which is basic even when it is used to represent repetitive acts. On the contrary, the generic subject implies consistency and universality. Thus, progressive and genericity will necessarily conflict with each other in coverage. If there is no relevant linguistic means to mediate, the structure will collapse. As a result, its acceptability will drastically reduce. Certainly if the progressive in (18) is interpreted as a gradually changing state, just as Fagan [9] has pointed out, example (18) will also be acceptable.

\section{Sports cars have sold quickly.}

Example (19) may be interpreted in the following two ways: one is the single past event, the other is the repetitive present event. If interpreted in the first way, it will lose the genericity, becoming an unacceptable expression; if in the second, just like example (15), it will be possible to create a generic interpretation, and become acceptable.

In all, from the out-layer of the semantic representation of middles, in the kind-referring middle construction, the interaction between the verb form and the NP is closely correspondent with the construction's genericity, and this correspondence has a great effect on the acceptability of middle construction.

In the intermediate layer, the interaction between SV structure and the genericity is mainly concerned with characterizing middle construction, for example:

20. This glass breaks easily.

In example (20), the subject NP" This glass" can receive either specific interpretation or generic interpretation. If receiving generic interpretation, its semantic structure can be described as:

\section{GEN [[This glass] [break] [easily]]}

It means: in general, for glass of this kind, its characteristics will let, cause or facilitate its breaking to become easy.

In this case, the acceptability of the expression's tense and aspectual performance is similar to example (15) - (19) .

If the subject NP receives a specific interpretation, then the expression can be described as:

\section{[This glass] [GEN [[break] [easily]]]}

It means: in general, for this piece of glass, its character will let, cause or facilitate its breaking to become easy at any time.

In this case the tense and aspectual performance of the verb gets greatly restrained.

21. a. This glass broke easily.

b. This glass is breaking easily.

c. This glass has broken easily.

Example (21a) is unacceptable, for the genericity of a characterizing sentence comes from the generalization of things or situations of the same kind. In cognitive sense, one cannot break the same piece of glass repeatedly, so the sentence in example (21) can only represent a single specific event, and this is conflicted with genericity of the middle construction. In the same way, example (21b), (21c) also has very low acceptability. Let's examine example (22):

22. a. This book is selling well.

b. This book has sold well.

c. This book sold well.

d. This book sells well.

Similar to the sentences in example (21), the subject NP in (22) cannot receive generic explanation. When it receives the specific explanation, things differ from the examples (15) (19), for the determiner "This" relieves the tension between the 
genericity of the NP and the genericity of the VP. As a result, there is no apparent conflict between the genericity of the NP and the genericity specified by the tone and aspect of the predicate verb. So all middle clauses in example (22) are totally acceptable.

Obviously, in the intermediate layer of the middle semantics, it is observable that there is a close correspondence between verb's formal performances and the subject-verb interaction in characterizing middles.

In short, the semantic interaction between the subject NP and the verb is a necessary condition for the genericity of the middle construction. The different tense and aspectual performance regulates the tension and conflict between the genericity of the NP and the genericity of the VP and thus there is no linear cause-effect correspondence between the genericity of the construction and the verb's tense and aspectual performances.

\section{CONCLUSION}

The genericity of the middle construction and the verb's tense and aspectual performances are not simply excusive, and decisively unidirectional, but mutually modifiable and compatible. The interaction between the subject NP and the predicate verb is a key factor influencing tense and aspect performances. The collocation of different genericity and different verb forms will produce different acceptability.

As a concept representing binary opposition, the defining feature intrinsically implies the unidirectional decision relationship among the multiple intrinsic characters. From the above, we cannot recognize genericity as one of the defining features of the middle construction and cannot ensure the relationship between genericity and the tense-aspect performances of the verb. On the contrary, the verb's tense and aspect performances can continually adjust and modify the genericity. Additionally, we can not verify the influence of the implicit agent on the verb's tense and aspect and the genericity of the construction. So it is arguable that the implicit agent is qualified as the defining feature of the middle construction. If distinctiveness is taken as a category of defining feature, it will become more liable that either genericity or the implicit agent is the defining feature, for we can not differentiate middles from other generic sentences, ergatives, non-ergatives, and accausatives.

\section{REFERENCES}

[1] Keyser, S. J \& T. Roeper.1984.On the middle and ergative constructions in English [J]. Linguistic Inquiry 15:381-416.

[2] Carrier, J. \&J.Randall.1992.The argument structure and syntactic structure of resultatives [J]. Linguistic Inquiry 23:173-234.

[3] Stroik, T.1992. Middles and movement [J]. Linguistic Inquiry 23:127-137.

[4] Stroik, T.1995. On middle formation: A reply to Zribi-Hertz [J]. Linguistic Inquiry 26:165-171.

[5] Stroik, T.1999. Middles and reflexivity [J]. Linguistic Inquiry 30:119-131

[6] Hoekstra, T. \& I. Roberts.1993. Middle construction in Dutch and English [A]. In E. Reuland \& W. Araham eds. Knowledge and
Language. Vol. 2, Lexical and Conceptual Structure [C].Dordrecht: Kluwer.

[7] Authier, J. M. \& L.Reed.1996.On the Canadian French middle[J]. Linguistic Inquiry 27:513-523.

[8] Roberts, I. 1985. The Representation of Implicit and Dethematized Subjects [D].Doctoral dissertation, University of Southern California, Los Angeles.

[9] Fagan, S.1988.The English middle [J]. Linguistic Inquiry 19:181-203.

[10] Fagan, S.1992. The Syntax and Semantics of Middle Constructions [M]. Cambridge: Cambridge University Press.

[11] Massam, D.1992. Null objects and non-thematic subjects [J]. Journal of Linguistics 28:115-137.

[12] Zribi-Hertz, A.1993.On Stroik's analysis of English middle constructions [J]. Linguistic Inquiry 24: 583-589.

[13] Achema, P. \& M. Schoorlemmer.1994.The middle construction and the syntax-semantics interface [J]. Lingua 93:59-90.

[14] Achema, P. \& M.Schoorlemmer.1995. Middles and nonmovement [J]. Linguistic Inquiry 26:173-197.

[15] Iwata, S.1999. On the status of an implicit arguments in middles [J]. Journal of Linguistics 35:527-553.

[16] Kimihiro, Y. \& John R., 2004, Taylor, What makes a good middle The role of qualia in the interpretation and acceptability of middle expressions in English $[\mathrm{J}]$, English Language and Linguistics 8.2:293-321

[17] Kristin, D. and Liesbetheyvaert, 2007, On the middle voice: an interpersonal analysis of the English middle [J], Linguistics 45-1: 37-83

[18] Kristin D. and Nele O. 2008, English middles with mental and verbal predicates: Towards a typology $[\mathrm{J}]$. English Text Construction 1:2 179-197.

[19] Wenzhong $\mathrm{He}, 2007$, Middle constructions in Chinese and west-germanic languages: towards a unified cognitive account $[\mathrm{M}], 21$, 172-176, Peiking: Science Press.

[20] Xiaojun Yang, 2008, A cognitive study of the middle constructions in English and Chinese - a corpus-based contrastive analysis [M], 150-162, Peiking: Foreign Language Teaching and Research Press.

[21] Hadumod, B. 2000, Routledge Dictionary of language and linguistics[M], 184, Peiking: Foreign Language Teaching and Research Press.

[22] Laura R. 2004, Habitual Sentences and Generic Quantification, in: WCCFL 23 Proceedings, ed. G. Garding and M. Tsujimura. Somerville, MA: Cascadilla Press.

[23] Shenghuan $\mathrm{Xu}, 2010$, Cognitive-pragmatic implications of the study of generic sentences[J], Foreign Language Teaching and Research 2: 83-91.

[24] Shenghuan Xu, 2010b, True or not: About Generic Sentence and Its Counter example [J], TCSOL Studies 1: 47-51.

[25] Chendan Liu, 2010, A Cognitive Explanation of Generic Sentences: Mental Model Selection Under the Control of the Generative Whole [J], Journal of PL A University of Foreign Languages : 1-6.

[26] Krifka, Manfred, Francis. J. Pelletier, Gregory. N. Carlson, Alice ter Meulen, Godehard Link, and Gennaro Chierchia. 1995. Genericity: An introduction, in G. N. Carlson and F. J. Pelletier (eds.), The generic book, 1-124.Chicago: The University of Chicago Press.

[27] Van Oosten. J. 1986. The nature of subjects, topics and agents: a cognitive explanation. Bloomington: Indiana University Linguistics Club.

[28] Ronald. W. langacker, 2001, Foundations of cognitive grammar (volume I, Theoretical prerequisites) [M], 283, 448-456, Peking: Peking university press.

[29] Ronald. W. langacker, 2004, Foundations of cognitive grammar (volume II , Descriptive application]) [M, 100, Peking: Peking university press.

[30] Condoravdi, C. 1989. The Middle: Where Syntax and Morphology Meet MIT Working Papers in Linguistics 11, 16-30.

[31] Jan-Wouter Zwart, 1997.On the Generic Character of Middle Constructions. NWO/University of Groningen. 